College as equalizer?

\title{
Testing the selectivity hypothesis
}

Karlson, Kristian Bernt

Published in:

Social Science Research

DOI:

10.1016/j.ssresearch.2018.12.001

Publication date:

2019

Document version

Peer reviewed version

Citation for published version (APA):

Karlson, K. B. (2019). College as equalizer? Testing the selectivity hypothesis. Social Science Research, 2019(80), 216-229. https://doi.org/10.1016/j.ssresearch.2018.12.001 


\title{
College as Equalizer?
}

\section{Testing the Selectivity Hypothesis}

\author{
Kristian Bernt Karlson (k@@ soc.ku.dk), Department of Sociology, University of \\ Copenhagen, Oester Farimagsgade 5, Building 16, DK-1014 Copenhagen K, Denmark
}

This version: October 23, 2018

\section{THIS PAPER IS TO BE PUBLISHED IN \\ SOCIAL SCIENCE RESEARCH}

Access accepted version here:

https://www.sciencedirect.com/science/article/pii/S0049089X17308244

Please notice:

This is a post-print (i.e. final draft post-refereeing) version according to SHERPA/ROMEO

Running head: College as Equalizer?

Keywords: education; college; social mobility; selectivity

Acknowledgements: The research leading to the results presented in this article has received funding from the European Research Council under the European Union's Seventh Framework Programme ([FP/2007-2013]/ERC grant 312906). 


\title{
College as Equalizer?
}

\section{Testing the Selectivity Hypothesis}

\begin{abstract}
Stratification research shows that occupational origins and destinations are weakly associated among individuals holding a college degree. The finding is taken to support the hypothesis that college equalizes opportunities and promotes social mobility. I test the competing hypothesis that the high level of social mobility reported for college degree holders results from the selectivity of this group. To control for selectivity, I reweigh a sample of college degree holders by the inverse probability of being a college degree holder conditional on observable characteristics of students before they enter college, including characteristics such as cognitive ability, personality traits, and beliefs about the future. Analyzing data from the National Longitudinal Survey of Youth 1979, I find no support for the selectivity hypothesis. These findings align with evidence based on indirect tests of the hypothesis, and indicate that college indeed appears to be an equalizer.
\end{abstract}




\section{College as Equalizer?}

\section{Testing the Selectivity Hypothesis}

\section{Introduction}

A widespread finding in social mobility research is that formal schooling facilitates occupational mobility between generations (Breen 2010; Breen and Jonsson 2005, 2007; Hout and DiPrete 2006; Ishida, Müller, and Ridge 1995; Yamaguchi 1983). This conclusion is perhaps most evident in the pioneering work by Hout (1988), who reported perfect social mobility - defined as independence between occupational origins and destinations-among individuals holding a four-year college degree. The finding was corroborated by Torche's (2011) extensive analyses of the meritocratic power of college, and by Pfeffer and Hertel (2015), who examine the impact of educational expansion on social mobility trends in the United States.

Yet, conclusions drawn about the meritocratic power of college in previous research hinge on a specific assumption about how students are sorted into college. The assumption implies that the educational selection process that sorts people into the group of college degree holders is as good as random (conditional on occupational origins). Scholars refer to the assumption as the assumption of no selective attrition (Holm and Jæger 2011; Lucas, Fucella and Berends 2011; Mare 1980, 1981, 1993, 2011; Torche 2011). Selective attrition arises as students who stay on in school are increasingly selected on both observed (e.g., occupational origins) and unobserved characteristics (e.g., cognitive ability). Increasing selectivity results in a downward bias in the estimated association between occupational origins and destinations among college graduates (Berk 1983; Cameron and Heckman 1998; Heckman 1979). As college degree holders arguably are a very selected group, the downward bias might be 
substantial and could therefore affect substantive conclusions about the mobility-promoting power of college. If college merely filters students on unobserved characteristics such as abilities and preferences, then college is a sorting mechanism that has little power in promoting social mobility.

In this paper, I provide an empirical test of the selectivity hypothesis, which holds that selective attrition accounts for the high levels of social mobility reported for college degree holders. Previous research has only provided indirect tests of this hypothesis. Torche (2011) argues that the selectivity hypothesis is not consistent with her reporting perfect mobility among college graduates. Torche (2011:801) finds that mobility among college degree holders did not decrease over time, as would have been expected given the marked expansion of college education after World War II.

Building on Torche's (2011) approach, this paper directly tests the selectivity hypothesis by explicitly correcting for the selectivity of college degree holders. Analyzing data from the National Longitudinal Survey of Youth 1979, I use inverse probability weights to yield social mobility estimates among college graduates that are corrected for non-random selection into the college graduate subsample using information on respondents' family background, skills, and expectations measured before they go to college. The empirical analysis shows that correcting for selective attrition has virtually no impact on the mobility estimates. I take this finding to support Hout's (1988) and Torche's (2011) finding that college indeed is an equalizer fostering social mobility. 


\section{Three Explanations of the Mobility-Promoting Power of College}

In his pioneering work, Hout (1988) reported perfect social mobility, defined as independence between occupational origins and destinations, among individuals holding a college degree. ${ }^{1}$ Hout (1988:35) concluded his analysis of the status attainment process in the 1980s as follows:

The effect of origins on destinations differs by level of education. The extreme case is college graduates. For them, current occupational status is independent of origin status. This finding provides a new answer to the old question about education's overcoming disadvantaged origins. A college degree can do it.

Previous research offers two substantive explanations and one methodological for why a college degree facilitates social mobility. The first substantive explanation emphasizes the demand side, arguing that the labor market segments that college graduates move into operate meritocratically (Breen and Jonsson 2007; Hout 1988; Torche 2011). In these segments, employers value formal qualifications over family-based connections in hiring processes, meaning that ascriptive processes have less room for operation. However, while the pattern reported by Hout (1988) is found in other post-industrial countries (Breen 2010; Breen and Jonsson 2007; Erikson and Jonsson 1998; Vallet 2004), research on the demand side of hiring does not provide unequivocal evidence in favor of this explanation. In their review of this topic, Bills, Di Stasio, and Gërxhani (2017) conclude that "educational credentials are surprisingly often not the linchpin of labor market success." They cite studies showing how non-

\footnotetext{
${ }^{1}$ In the literature on the mediating role of education in social mobility, Hout's finding is often referred to as the compositional effect of education (Breen 2010; Breen and Jonsson 2007). If origins and destinations are independent among highly educated individuals, then as larger fractions of cohorts attain higher education, social mobility would be expected to increase over time. I return to this point in the Discussion section.
} 
meritocratic characteristics, including cues of class advantage, affect who gets hired among the highly educated (e.g., Jackson 2007, 2009; Petersen, Saporta, and Seidel 2000; Rivera 2011, 2012; Rivera and Tilcsik 2016).

Moreover, Torche (2011) reports direct evidence against the demand side explanation. She finds that although the origins-destinations association decreases with educational attainment across most of the educational distribution, it appears to increase again for individuals who complete an advanced degree (i.e., it follows a U-shape pattern). Advanceddegree holders consequently experience lower mobility than regular college degree holders. As advanced-degree holders have more specialized skills than regular college graduates, they should be even less affected by ascriptive factors. Thus Torche's (2011) analysis provides little support for this explanation.

The second substantive explanation stresses the supply side, reasoning that because college fosters human and social capital independently of family background, such capital accumulation allows students from lower-class backgrounds to overcome any initial disadvantage (Torche 2011). Research in both economics and sociology largely supports this explanation. Card (1999) reports that the marginal economic returns to schooling are higher among disadvantaged students (for a recent example, see also Zimmerman 2014). Brand and Xie (2010) similarly find that those least likely to attend college benefit most from attending. Moreover, in his review of the literature on the returns to college, Hout (2012) concludes that, on balance, evidence is in favor of larger causal effects of college on earnings among those who are less likely to attain a college degree. ${ }^{2}$ Hout (2012) also cites research reporting

\footnotetext{
${ }^{2}$ Hout (2012) notes that the verdict is still out whether this pattern-known as the negative selection hypothesis-is true. A similar point has recently been raised by Breen, Choi, and Holm (2015) (see also Carneiro, Heckman, and Vytlacil 2011). Hout (2012), moreover, emphasizes that the larger college effects found for those less likely
} 
independent college effects on social capital, including the study by Brand (2010) who finds larger effects on civic participation among those who are less likely to go to college.

While both substantive explanations assume that college causes high mobility, the methodological explanation argues that the observed pattern of perfect mobility results from selectivity bias, not from a genuine effect of college education (Torche 2011). This bias arises as a consequence of the increased selectivity of students who stay on in school. ${ }^{3}$ At the college level, students are highly selected both on occupational origins and on unobserved characteristics such as cognitive ability, personality traits, or educational aspirations. Research shows that this selectivity induces a negative correlation between observed and unobserved characteristics among college graduates, net of any correlation existing in the full cohort of students (Cameron and Heckman 1998; Mare 1981, 1993). The negative correlation results in a downward bias in the estimated association between occupational origins and destinations. As the intergenerational occupation association measures lack of mobility, the bias means that the level of social mobility will be overstated if the methodological explanation is true.

Previous research has provided very few empirical tests of the methodological explanation, which emphasizes selectivity bias as an explanation for the high mobility levels reported for college degree holders. Torche (2011:801) provides good arguments against the selectivity hypothesis, reporting that the level of mobility among college degree holders did not decrease over time, as would have been expected given the substantial expansion of tertiary education after World War II, which should have made college less selective over time.

to go to college do not pertain to students who are very unlikely to enroll in college, but rather those in the middle of the ability distribution, that is, those who are somewhat likely.

${ }^{3}$ Also known as sample selection bias or dynamic selection bias, this bias has been discussed in the 2011 special issue on unobserved heterogeneity in educational transition models, Research on Social Stratification and Mobility, edited by M. Buis. 
Although this argument provides indirect evidence against the hypothesis, it does not provide a direct, empirical test. This paper provides such test by exploiting information on students before they go to college to learn about how the non-random selection into the sample graduating from college affects the association between origins and destinations among college graduates.

\section{The Logic of Selective Attrition}

Before I present the approach that I use for correcting for selective attrition, I conduct a simple simulation study that illustrates how selective attrition leads to a downward bias in the estimated association between origins and destinations among college degree holders. The simulations are based on Heckman's (1979) notion of sample selection bias as a specification error (see also Berk 1983; Wooldridge 2010:777ff). However, as Mare (2011) observes, referring to "bias" in the context of estimating a descriptive association such as that between occupational origins and destinations requires that one clearly specifies what the true or underlying association would be (or more precisely, what the true or underlying model that generates this association would be). In the context of this paper, it is the origins-destinations association that would be observed if one was able to correct for the non-random selection into the sample of college degree holders, that is, if college degree holders were drawn randomly from the full student population.

I consequently treat social origins as an exogenous covariate and use the total effect of social origins on destinations as my measure of social mobility. Treating social origins as an exogenous variable is conventional in the social mobility literature and is usually justified by 
the notion that individuals have no control over the socio-economic conditions into which they are born. From this perspective, social origins are exogenous to the individual. ${ }^{4}$

The simulation study reflects two fundamental scenarios in terms of how selective attrition may affect the estimated origins-destinations association. First, it may be that the association is constant across levels of schooling. Put differently, the association is the same for all in the population and does not depend on the level of attained schooling. Second, it may be that the association declines across schooling levels such that the association is weaker at higher levels. The simulation study covers both scenarios and estimates, for each scenario, the bias in the origins-destinations association when the association is calculated on a selected sample.

For both scenarios, I specify a data-generating sample selection model in which schooling, $S$, is determined by social origins, $O$; unmeasured variables, $U$, which are independent of $O$; and a random error, $e$ :

$$
S=\gamma_{1} O+\gamma_{2} U+e
$$

$U$ could be academic ability, which would mean that both origins and ability predict schooling. However, because $U$ is assumed to be independent of $O$-which follows the canonical specification of sample selection bias in the literature (Cameron and Heckman 1998; Heckman 1979) $-U$ captures the portion of unmeasured heterogeneity that is unrelated to origins. If $U$ was a measure of academic ability, it would be the portion of the variation in ability that is unrelated to origins (i.e., $\gamma_{2}$ would capture the independent impact of ability on schooling, net

\footnotetext{
${ }^{4}$ Social origins may however also be treated as endogenous, either from the perspective of the selection of populations over multiple generations, as Mare and Maralani (2006) convincingly demonstrate, or from a causal perspective examining the causal effects of say parents' schooling on children's schooling. As these perspectives are very different from the research question I analyze in this paper, I do not pursue them any further.
} 
of origins). While this property of the model may appear counterintuitive, its purpose in the sample selection model is simply to show how an unmeasured variable, which is uncorrelated with origins in the population, will be correlated in the selected sample of college graduates. ${ }^{5}$ As I show below, this correlation in the selected sample induces a bias that is caused solely by the sample selection mechanism, not by any type of conventional confounding or selection bias (see Heckman 1979).

For Scenario 1, I specify a data-generating outcome model in which social destinations, $D$, are determined by social origins, $O$, unmeasured variables, $U$, and a random error, $v$ :

$$
D=\beta_{1} O+\beta_{2} U+v
$$

In this data-generating model, which pertains to the full population, I maintain the assumption that $O$ and $U$ are independent of each other, and I further assume that the random errors in Equations (1) and (2), $v$ and $e$, are independent of each other. The specification of this model implies that the effect of origins on destinations is constant in the population (i.e., it is the same for everyone), and therefore does not depend on the level of schooling. To gauge the impact of sample selection on the estimated association among college degree holders for Scenario 1, I simulate a dataset using Equations (1) and (2). $O, U, e$, and $v$ are all assumed to be standard normal variables with zero mean and unit variance, and I set all parameters in the equations to equal unity.

For Scenario 2, I use the same definitions of the variables, but specify a different datagenerating outcome model,

$$
D=\delta_{1} O+\delta_{2} S^{*}-\delta_{3} S^{*} O+\delta_{4} U+v
$$

\footnotetext{
${ }^{5}$ In the statistical literature, this assumption is known as a random effects assumption (Cameron and Heckman 1998:270).
} 
in which the effect of origins declines with schooling. For this scenario, I again draw the variables from a standard normal distribution, but in this model, I set the parameters to $\gamma_{1}=\gamma_{2}=\delta_{1}=\delta_{2}=\delta_{4}=1$ and $\delta_{3}=0.25$. This specification amounts to saying that the true effect of origins on destinations for non-college-degree holders is 1 , whereas the true effect for college degree holders is $1-0.25=0.75$, thereby reflecting the situation in which the true effect declines across schooling levels.

In the spirit of Heckman (1979), for both scenarios I now assume that I only observe social destinations among those who attain a college degree. In the simulations, this assumption is equivalent to assuming that I only observe the social destinations outcome for those who are above a certain educational threshold, governed by the following threshold or sample selection rule,

$$
\begin{aligned}
& S^{*}=0 \text { if } \quad S \leq \tau \\
& S^{*}=1 \quad \text { otherwise, }
\end{aligned}
$$

where $\tau$ is a threshold parameter. If $S$ was a measure of years of schooling, a threshold parameter of 15 would cut the schooling variable into two groups, one without and the other with a college degree. In both scenarios, I choose two threshold parameters that correspond to 15 and 30 percent of a cohort completing college, respectively. I choose this strategy to evaluate the extent to which the selectivity of college affects substantive conclusions about the mobilitypromoting capacity of college.

In light of the specifications of the two scenarios, my expectation is that the originsdestinations association will be downwardly biased in the sample of college degree holders (Heckman 1979). As Cameron and Heckman (1998) notes, the sample selection process in Equation (1) creates a negative correlation between $O$ and $U$ in the selected sample. The reason is that individuals with high values on $O$ and $U$ will be overrepresented in the sample (e.g., 
socially advantaged and high-ability students will be overrepresented) (Berk 1983). This overrepresentation mechanically induces a negative correlation between $O$ and $U$ in the sample, although the two are independent of each other in the population. Given the conventional formula for omitted variable bias, this negative correlation in turn attenuates the estimated origins-destinations association in the selected sample (i.e., the effect of $O$ on $D$ in the sample). ${ }^{6}$

Table 1 provides results from the simulation study, which is based on 1,000,000 randomly drawn observations. In Scenario 1, the true origins-destinations association is 1 for both college degree holders and for those who do not hold a college degree, whereas the estimated association among college degree holders is substantially lower at about two-thirds. The bias is substantial and of similar magnitude irrespective of whether 15 or 30 percent of a cohort completes college. Moreover, as the estimated association among those not holding a college degree is substantially larger, the estimated associations in Scenario 1 reveal a pattern of declining effects. Consequently, selective attrition can produce declining originsdestinations associations across schooling levels, even when such trend does not exist.

In Scenario 2, the true origins-destinations association is 1 for those who do not hold a college degree and 0.75 for those who do. As we would have expected, the estimated association for the college degree holders is about 0.4 and substantially lower than the true 0.75. Moreover, selective attrition appears to exacerbate the pattern of declining effects across levels of schooling compared to the true pattern. In sum, both scenarios suggest that selective attrition can account for declining origins-destinations associations across levels of schooling.

\footnotetext{
${ }^{6}$ This is also why Heckman (1979) considers sample selection bias a specification error, as it induces omitted variable bias in the selected sample.
} 
This property poses serious challenges to the finding of perfect social mobility among college degree holders.

\begin{tabular}{lcccc}
\hline & \multicolumn{2}{c}{ College Degree Holders } & \multicolumn{2}{c}{ Non-College Degree Holders } \\
\cline { 2 - 5 } & Estimated & True & Estimated & True \\
\hline$\underline{\text { Scenario 1 }}$ & 0.64 & 1.00 & 0.86 & 1.00 \\
15 percent of cohort & 0.68 & 1.00 & 0.79 & 1.00 \\
30 percent of cohort & & & & \\
Scenario 2 & 0.39 & 0.75 & 0.86 & 1.00 \\
15 percent of cohort & 0.43 & 0.75 & 0.79 & 1.00 \\
30 percent of cohort & & & & \\
\hline
\end{tabular}

\section{Table 1. Results from Simulation Study of the Consequences of Selective Attrition.}

Notes: Simulated data based on 1,000,000 observations. In Scenario 1, the true effect of origins on destinations is the same for all individuals in the population. In Scenario 2, the true effects are 1 for non-college degree holders and 0.75 for college degree holders.

\section{Testing the Selectivity Hypothesis}

To test whether selective attrition can explain the high levels of social mobility reported for college degree holders, I use inverse probability weighting (IPW) to correct for non-random selection into the sample of college graduates (Seaman and White 2013; Wooldridge 2010:821827). ${ }^{7}$ The principle is to reweigh the selected sample such that its distribution on observed covariates is more or less identical to the distribution in the full sample. Those who are less likely to complete college given their observed characteristics are given larger weights and

\footnotetext{
${ }^{7}$ For a sociological example using IPWs to correct for sample selection, see Lawrence and Breen (2016). Note that IPWs are also used for estimating causal effects from observational data (Cole and Hernan 2008), and for correcting survey nonresponse (Wooldridge 2010).
} 
those who are more likely are given smaller weights. The method provides a type of counterfactual inference in that we can obtain estimates of a given association between two variables in a selected sample, had this sample been drawn randomly from the population. The method is semiparametric and follows a straightforward procedure in three steps:

1. Estimate individual $i$ 's probability, $p_{i}$, of being in the selected sample conditional on observed covariates. The probability is usually estimated using a logit or probit model.

2. Construct the inverse probability of being in the sample. For those in the selected sample, the inverse probability is given by $1 / p_{i}$, whereas for those not in the sample, it is given by $1 /\left(1-p_{i}\right)$.

3. Estimate a weighted regression on the selected sample using the estimated IPW from the first two steps as weights.

In this paper, I apply this method to estimate the origins-destinations association using a weighted regression that weights by the inverse probability of being a college graduate. This approach allows me to assess what the origins-destinations association would look like, if the selection in to the college graduate sample was as good as random.

A key assumption underlying the use of IPW is that of ignorability; that is, conditional on the observed covariates, the selection into the sample of college degree holders is as good as random (Wooldridge 2010:821-827). This assumption will be violated if unmeasured factors other than those proxied by the covariates predict college completion. As this assumption cannot be tested, the credibility of using IPW to correct for sample selection depends on the extent to which we believe that the included covariates capture the non-random selection into the sample of college degree holders. In my empirical analyses, I include a range of individual and family background characteristics that previous research has found to affect college 
completion. Although I cannot rule out that further unmeasured covariates are important for college completion, I take my covariates to form reasonable proxies for major determinants of graduating from college.

\section{Data and Methods}

I analyze data from the National Longitudinal Survey of Youth 1979 (NLSY79), a national probability sample of Americans aged 14-22 in 1979 through 2012. The original sample is interviewed every year from 1979 through 1994 and every second year since 1994. Because the NLSY79 collects rich information on a subsample of adolescents before they go to college, the data are very well suited for testing the selectivity hypothesis. To ensure that I measure respondents' characteristics before they go to college, in the analysis of college degree holders, I restrict the sample to those aged 14-16 in 1979. The resulting analytical sample comprises 4,070 respondents. To make the sample representative of the population, I use the sampling weights provided in the 1979 survey, and I use multiple imputation to retain as many observations as possible (using 25 datasets) ${ }^{8}$ All standard errors are corrected for the clustering of respondents within households.

\section{Measures}

I measure occupational origins with Duncan's socioeconomic index (SEI; hereafter referred to as SES). Parents' occupational information is provided in the 1979 wave, and I use the highest SES score reported by any of the two parents. I measure occupational destinations as the average SES score reported from 1998 through 2012 (i.e., from ages 33-35 through ages 47-

\footnotetext{
${ }^{8}$ In the empirical analysis investigating intergenerational associations, to increase efficiency, I follow von Hippel (2007) and, after imputing missing variables, delete respondents with missing values on the dependent variable.
} 
49). ${ }^{9}$ In the empirical analysis, I standardize both SES variables to zero mean and unit variance using the full sample as the basis of standardization. I measure educational attainment as the highest grade ever reported from 1990 through 2000 (i.e., from ages 25-27 through ages 3537). I subsequently recode this educational attainment variable into a college completion dummy using 16 years of schooling as the cut-point.

In addition to occupational origins and destinations, I follow Torche (2011) and also include corresponding measures using family income. I measure income origins as the log of parents' total family net income in 1979 , and income destinations as the log of respondent's average family income in 1997, 1999, 2001, 2003, 2005, 2007, and 2009 (i.e., from ages 3234 through 44-46). Both income variables are measured in 2017 USD. The estimated associations using family income are intergenerational income elasticities, which can be interpreted as the fraction of the income inequality in the parents' generation that is passed on to the children's generation.

To construct the inverse probability of graduating from college, I include several characteristics of adolescents, which are measured before they go to college and which have been used in previous research on educational attainment. In selecting relevant variables, I draw on research examining (a) selection into college (Brand and Xie 2010; Roksa et al. 2007); (b) the importance of cognitive skills and personality traits for educational attainment (Farkas 2003; Heckman, Stixrud, and Urzua 2006; Jencks 1972); (c) how adolescents' expectations and their parents' encouragement affect educational decisions (Morgan 2004; Sewell, Haller

\footnotetext{
${ }^{9}$ To test the robustness of my results, I have conducted analyses using the highest SES value ever reported in the time span instead of the average SES value (available upon request). Conclusions are nonetheless unaffected by changing the SES variable, suggesting that my findings are robust vis-à-vis alternative measures.
} 
and Portes 1969); and (d) the effects of cultural capital on educational success (DiMaggio 1982).

I include a measure of cognitive ability, which is the Armed Forces Qualification Test that gauges arithmetic reasoning, mathematics knowledge, word knowledge, and paragraph comprehension. This test was administered in 1980, when the respondents in my final analytical sample were 15 to 17 years old. It would have been preferable to have a measure of abilities at even earlier ages, as a minor fraction of the restricted sample might have entered college. If college affects cognitive abilities, then reverse causation may bias the reported estimates. However, among this minor proportion of respondents, most of them would be in their first year and the potential impact of college would be small. ${ }^{10}$ I standardize the cognitive ability measure to zero mean and unit variance using the full sample as the basis of standardization.

I measure personality traits using Rotter's internal-external locus of control scale (tapped in 1979) and Rosenberg's self-esteem scale (tapped in 1980). I include these measures because research suggests that personality traits predict educational outcomes (Borghans et al. 2008), and may therefore also be important for filtering students into college. High values on the Rosenberg's scale indicate high levels of self-esteem, whereas high values of Rotter's scale refer to high levels of external control. I standardize both personality measures to zero mean and unit variance using the full sample as the basis of standardization. I include a crude measure of cultural capital, which is a simple summated scale of three items measuring whether at age 14 the respondent's household (a) regularly received magazines, (b) regularly received

\footnotetext{
${ }^{10}$ One solution to this issue would be to restrict the sample to those aged 14 to 15 in 1979 , but this comes at a price of much larger standard errors. Thus, I balance the tradeoff between bias and variance by also including 16year-olds in 1979. Supplementary analyses also suggest that the substantive conclusions do not differ between these different sample restrictions (see the Analysis section).
} 
newspapers, or (c) held a library card. ${ }^{11} \mathrm{I}$ standardize the measure to zero mean and unit variance using the full sample as the basis of standardization.

I include three measures that tap into the social-psychological component of the status attainment process and which have been found to have strong, independent effects on educational attainment. First, I measure the respondent's educational expectations with a question administered in 1979 about the highest grade the student thinks he or she will complete (measured in years of schooling). Second, I include an equivalent measure of the respondent's best friend's educational expectations (measured in years of schooling). Third, I include a dummy variable measuring in 1979 the self-perceived influence of significant others on the respondent's decision to enroll in college, with 1 being some or a high degree of influence and 0 being minor influence of none at all. ${ }^{12}$ I refer to this variable as "significant others' influence" (Sewell et al. 1969).

In addition to these measures that tap into the adolescents' skills, beliefs, and home environments, I also include background characteristics other than occupational origins (Brand and Xie 2010). These include the respondent's gender and race/ethnicity (White, Black, or Hispanic), father's years of schooling, mother's years of schooling, number of siblings, a dummy variable for intact family status, a dummy variable for whether a foreign language was spoken in the house during childhood, and a rural-urban indicator based on the Standard Metropolitan Statistical Area (SMSA) in which the respondent lived in $1979 .{ }^{13}$ I include these

\footnotetext{
${ }^{11}$ A principal components analysis using tetrachoric correlations shows that the first component can account for about two-thirds of the total variance in the three items. As the component loadings are very similar for this first component, I choose to make a simple summated scale. Cronbach's alpha is 0.55.

12 The 1979 NLSY survey first asks the respondent to select the most significant others (e.g., parents, siblings, friends) and then asks the respondent to rate the influence of this (these) significant other(s) on his or her decision not to attend college. I use the latter variable in a recoded version, as described in the main text.

${ }^{13}$ The rural-urban indicator is grouped into four categories: (1) not in SMSA, (2) SMSA — not a central city, (3) SMSA — central city unknown, and (4) SMSA — in central city.
} 
characteristics because they all predict college completion, and therefore may bias the originsdestinations association among college degree holders. Including gender also allows me to run the analysis by gender, which is the approach that Torche (2011) uses.

\subsection{Analytical Strategy}

I divide the empirical analysis into four sections. In the first section, I characterize the selection into the college degree holder sample on the variables described earlier. I use descriptive statistics and a logit model for this purpose. The logit model is also used for constructing the inverse probability weight that I apply in the subsequent analyses. In the second section, I report

the estimated origins-destinations associations using the conventional approach (with no correction for the selectivity of college graduates) and using the IPW approach. If the selectivity hypothesis is true, then the IPW-corrected estimates of the association should be positive and statistically significant at conventional significance levels. In the third section, I analyze the origins-destinations association among those with an advanced degree to see whether I can corroborate Torche's (2011) finding that the association reemerges for this highly selected group. In the fourth section, to further test the selectivity hypothesis, I present the results from an analysis that examines family income instead of occupational status.

\section{Analysis}

\subsection{Who Holds a College Degree?}

Table 2 reports descriptive statistics for the full student cohort aged 14 to 16 in 1979, and for the subsample of respondents who hold a four-year college degree. College degree holders, which constitute about 26 percent of the cohort, are much more selected on family background, cognitive and non-cognitive abilities, and educational expectations. For example, college degree holders more often come from high-SES families, have better cognitive skills, and have 
higher self-esteem than the average person in the cohort. Moreover, Whites are also overrepresented among college degree holders compared to Blacks and Hispanics. These numbers speak to the very selected nature of college degree holders.

In Table 3, I report estimates from a logit model predicting whether a person graduates from college as a function of his or her characteristics. ${ }^{14}$ The effects of roughly half of the included predictors are statistically significant at a 5-percent level and they support the overall pattern of findings reported for Table 2. For example, net of the other covariates, occupational origins have a positive and statistically significant effect on college completion. In terms of effects on the probability margin (reported as average marginal effects [AME] in Table 3), for a standard deviation change in origin SES, the probability of completing college increases by about 4.1 percentage points on average, net of the other variables in the model. However, in contrast to the pattern reported in Table 2, Blacks are about 11.3 percentage points more likely to complete college than Whites on average, net of the other variables. This result confirms the result of previous research that, among Blacks and Whites with similar family background and skills, Blacks are more likely than Whites to complete college (see Roksa et al. 2007).

\footnotetext{
${ }^{14}$ For some of the variables, the model in Table 3 includes squared terms. Their inclusion results from a model search in which I tested squared terms for all continuous predictors. I use the same approach for specifying the logit models in all subsequent analyses.
} 


\begin{tabular}{|c|c|c|c|c|}
\hline & \multicolumn{2}{|c|}{ Population } & \multicolumn{2}{|c|}{ College Degree Holders } \\
\hline & Mean & $\mathrm{SD}$ & Mean & SD \\
\hline$\%$ College graduates ${ }^{b}$ & 0.256 & - & - & - \\
\hline Origin SES & 0 & 1 & 0.679 & 0.922 \\
\hline Destination SES & 0 & 1 & 0.820 & 0.767 \\
\hline Origin family income $(\log )^{\mathrm{c}}$ & 11.075 & 0.925 & 11.356 & 0.675 \\
\hline Destination family income $(\log )^{\mathrm{c}}$ & 11.008 & 0.761 & 11.715 & 0.651 \\
\hline Cognitive ability & 0 & 1 & 0.882 & 0.853 \\
\hline Locus of control (Rotter) & 0 & 1 & -0.281 & 0.966 \\
\hline Self-esteem (Rosenberg) & 0 & 1 & 0.344 & 1.002 \\
\hline Cultural capital & 0 & 1 & 0.443 & 0.703 \\
\hline Educational expectations & 13.893 & 2.278 & 15.757 & 1.683 \\
\hline Friends' educational expectations & 13.889 & 2.172 & 15.245 & 1.851 \\
\hline Significant others' influence ${ }^{\mathrm{d}}$ & 0.714 & - & 0.885 & - \\
\hline$\%$ Male & 0.510 & - & 0.503 & - \\
\hline \multicolumn{5}{|l|}{ Race } \\
\hline$\%$ White & 0.792 & - & 0.889 & - \\
\hline$\%$ Black & 0.141 & - & 0.079 & - \\
\hline$\%$ Hispanic & 0.067 & - & 0.032 & - \\
\hline Father's schooling & 11.681 & 3.569 & 14.005 & 3.373 \\
\hline Mother's schooling & 11.551 & 2.731 & 13.197 & 2.495 \\
\hline Number of siblings & 3.248 & 2.282 & 2.549 & 1.693 \\
\hline$\%$ Intact family & 0.709 & - & 0.814 & - \\
\hline$\%$ Foreign language in home & 0.129 & - & 0.123 & - \\
\hline \multicolumn{5}{|l|}{ Rural-urban indicator } \\
\hline$\%$ Not in SMSA (ref.) & 0.299 & - & 0.271 & - \\
\hline$\%$ SMSA — not a central city & 0.340 & - & 0.406 & - \\
\hline$\%$ SMSA - central city unknown & 0.206 & - & 0.200 & - \\
\hline$\%$ SMSA — in central city & 0.156 & - & 0.122 & - \\
\hline
\end{tabular}

Table 2. Descriptive Statistics (Means and Standard Deviations ${ }^{\mathrm{a}}$ )

Notes: Respondents aged 14-16 in 1979. Multiple imputation and 1979 sampling weights used.

aStandard deviations calculated as the square root of $E\left(X^{2}\right)-E(X)^{2}$, where each moment is the average of the 25 imputed datasets.

${ }^{\mathrm{b}}$ College degree holders defined as having completed at least 16 years of schooling.

cFamily income measured in 2017 USD.

${ }^{\mathrm{d}} \mathrm{A}$ binary variable indicating high (1) or low (0) influence; see the main text for a detailed description. 


\begin{tabular}{|c|c|c|c|c|}
\hline & \multicolumn{2}{|c|}{ Logit Coefficients } & \multicolumn{2}{|c|}{ AME } \\
\hline & $\mathrm{b}$ & $\mathrm{SE}$ & $\mathrm{b}$ & $\mathrm{SE}$ \\
\hline Origin SES & $0.373 * * *$ & 0.092 & $0.041 * * *$ & 0.010 \\
\hline Origin family income (log) & 0.115 & 0.137 & 0.013 & 0.015 \\
\hline Cognitive ability & $1.052 * * *$ & 0.094 & 0.115 & 0.009 \\
\hline Locus of control & -0.046 & 0.072 & -0.001 & 0.008 \\
\hline Locus of control squared & $-0.121 *$ & 0.055 & - & - \\
\hline Self-esteem & 0.034 & 0.076 & 0.004 & 0.008 \\
\hline Cultural capital & 0.105 & 0.084 & 0.011 & 0.009 \\
\hline Educational expectations & $0.284 * * *$ & 0.043 & $0.031 * * *$ & 0.004 \\
\hline Friends' ed. expectations & $1.889 * *$ & 0.654 & 0.005 & 0.004 \\
\hline Friends' ed. expectations squared & $-0.063 * *$ & 0.023 & -- & -- \\
\hline Significant others' influence & $0.414^{*}$ & 0.179 & $0.045^{*}$ & 0.019 \\
\hline Male & -0.133 & 0.138 & -0.015 & 0.015 \\
\hline \multicolumn{5}{|l|}{ Race } \\
\hline White (ref.) & - & - & - & - \\
\hline Black & $1.112 * * *$ & 0.301 & $0.128 * * *$ & 0.033 \\
\hline Hispanic & -0.266 & 0.392 & -0.031 & 0.045 \\
\hline Father's schooling & 0.038 & 0.032 & 0.004 & 0.003 \\
\hline Mother's schooling & -0.205 & 0.146 & $0.014 * * *$ & 0.004 \\
\hline Mother's schooling squared & $0.014 *$ & 0.006 & - & - \\
\hline Number of siblings & $-0.068 *$ & 0.034 & $-0.007^{*}$ & 0.004 \\
\hline Intact family & 0.236 & 0.178 & 0.026 & 0.019 \\
\hline Foreign language in home & $0.520 *$ & 0.240 & $0.059 *$ & 0.028 \\
\hline \multicolumn{5}{|l|}{ Rural-urban indicator } \\
\hline Not in SMSA (ref.) & - & - & - & - \\
\hline SMSA - not a central city & -0.165 & 0.172 & -0.019 & 0.019 \\
\hline SMSA - central city unknown & $-0.593 * *$ & 0.202 & $-0.064 * *$ & 0.003 \\
\hline SMSA - in central city & -0.259 & 0.232 & -0.029 & 0.026 \\
\hline Intercept & $-20.685^{* * *}$ & 4.963 & - & - \\
\hline Pseudo R-squared $^{\mathrm{a}}$ & $40.2 \%$ & & & \\
\hline
\end{tabular}

Table 3. Logit Model Predicting Probability of Graduating from College (Logit Coefficients and Average Marginal Effects)

Notes: Respondents aged 14-16 in 1979. Multiple imputation and 1979 sampling weights used.

${ }^{a}$ Average McFadden's pseudo R-squared over the 25 imputations.

$* \mathrm{p}<0.05 ; * \mathrm{p}<0.01 ; * * \mathrm{p}<0.001$. 


\subsection{Social Mobility among College Degree Holders}

I use the logit model reported in Table 3 to predict the probability of completing college. In

Table 4, I report the estimated origins-destinations association using weighted regressions based on the inverse probability of completing college. Table 4 also reports the uncorrected estimates and estimates of the association in the full analytical sample (i.e., all respondents aged 14-16 in 1979). I find that the origins-destinations association in the full sample is about 0.31, suggesting that for a standard deviation change in origin SES, the expected change in destination SES is about one-third of a standard deviation. This estimate differs little by gender and is in line with that reported by Torche (2011) using the same dataset.

\begin{tabular}{|c|c|c|c|c|c|c|}
\hline & \multicolumn{2}{|l|}{ All } & \multicolumn{2}{|l|}{ Men } & \multicolumn{2}{|l|}{ Women } \\
\hline & $\mathrm{b}$ & SE & $\mathrm{b}$ & SE & $\mathrm{b}$ & SE \\
\hline Full sample & $0.312 * * *$ & 0.021 & $0.357 * * *$ & 0.030 & $0.261 * * *$ & 0.029 \\
\hline \multicolumn{7}{|c|}{ College degree holders } \\
\hline Uncorrected & 0.036 & 0.035 & 0.059 & 0.095 & -0.013 & 0.077 \\
\hline IPW-corrected & 0.023 & 0.069 & 0.002 & 0.109 & -0.0003 & 0.071 \\
\hline \multicolumn{7}{|c|}{ College Degree Holders wo/ Advanced Degree } \\
\hline Uncorrected & -0.023 & 0.046 & -0.019 & 0.066 & -0.028 & 0.051 \\
\hline IPW-corrected & -0.071 & 0.116 & -0.045 & 0.162 & -0.073 & 0.117 \\
\hline \multicolumn{7}{|c|}{$\begin{array}{l}\text { Table 4. Intergenerational SES Association in Full Sample, among College Degree } \\
\text { Holders and College Degree Holders without an Advanced Degree (Regression } \\
\text { Coefficients and Standard Errors) } \\
\text { Notes: Respondents aged } 14-16 \text { in } 1979 . \text { Multiply imputed data using } 25 \text { datasets. Estimates corrected for } \\
\text { complex survey design. } \\
\text { aEstimates from logit model predicting selection into this sample are reported in anpendix Table A1. }\end{array}$} \\
\hline
\end{tabular}


Among college degree holders, the uncorrected association is close to zero and statistically insignificant, again being consistent with Torche's (2011) findings. However, the IPW-corrected estimate of the origins-destinations association is also close to zero and statistically insignificant at a 5-percent level. I find this null effect for both men and women. In sum, the results reported in Table 4 provide strong evidence against the selectivity hypothesis: College does indeed appear to be an equalizer promoting social mobility.

To further test the selectivity hypothesis and the robustness of my findings, I conduct two additional analyses, both of which present clear evidence against the selectivity hypothesis. First, in the lower panel of Table 4, I report estimates of the occupational origins-destinations association among college degree holders without an advanced degree. ${ }^{15} \mathrm{In}$ contrast to Hout (1988), Torche (2011) makes this distinction between college degree holders with and without an advanced degree. However, as Table 4 shows, the uncorrected and IPW-corrected estimates are all close to zero and statistically insignificant, suggesting that selectivity is a poor candidate for explaining the high levels of mobility among college degree holders without an advanced degree.

Second, one drawback of using inverse probability weights to correct for sample selection is that the correction tends to produce large standard errors (i.e., it is statistically inefficient). This property of the method is also evident from the estimates reported in Table 4. To test the robustness of my results associated with this potential issue, I reproduce the empirical analysis by extending my analytical sample to respondents aged 14 to 18 in 1979 instead of those aged 14 to $16 .{ }^{16}$ Still, the pattern of findings from these supplementary

\footnotetext{
15 This group constitutes about 15 percent of the full cohort (i.e., the group who has completed exactly 16 years of schooling). In Appendix Table A2, I report estimates from the logit model predicting the probability of being in this sample.

${ }^{16}$ The size of this extended analytical sample is 7,193 respondents.
} 
analyses-reported in appendix Table A1-is virtually identical to that reported in Table 4. Taken together, the two additional analyses corroborate the overall finding that college promotes occupational mobility.

\subsection{Social Mobility among Advanced Degree Holders}

A key finding in Torche (2011) is that the occupational origins-destinations association reemerges among advanced degree holders for men. Torche's (2011) finding is important for at least two reasons. First, if the selectivity hypothesis is true, then we would not expect the association to reappear for this very selected group. Second, if the substantive explanation emphasizing the demand side of education is true, then we would also not expect the association to reappear, as this group arguably enters very meritocratic segments of the labor market. Thus, examining social mobility among advanced degree holders potentially provides important insights into whether higher schooling levels promote mobility.

\begin{tabular}{lllllll}
\hline & \multicolumn{2}{c}{ All } & \multicolumn{2}{c}{ Men } & \multicolumn{3}{c}{ Women } \\
\cline { 2 - 7 } & $\mathrm{b}$ & SE & $\mathrm{b}$ & SE & $\mathrm{b}$ & $\mathrm{SE}$ \\
\hline Full sample & $0.312^{* * *}$ & 0.021 & $0.357^{* * * *}$ & 0.030 & $0.261^{* * * *}$ & 0.029 \\
Advanced degree holders & & & & & & \\
Uncorrected & 0.072 & 0.052 & 0.098 & 0.067 & 0.027 & 0.086 \\
IPW-corrected & -0.005 & 0.084 & 0.002 & 0.129 & -0.017 & 0.092 \\
\hline
\end{tabular}

\section{Table 5. Intergenerational SES Associations in Full Sample and among Advanced} Degree Holders (Regression Coefficients and Standard Errors)

Notes: Respondents aged 14-16 in 1979. Multiply imputed data using 25 datasets. Estimates corrected for complex survey design. Appendix Table A3 shows estimates from the logit model predicting the probability of holding an advanced degree.

$* \mathrm{p}<0.05 ; * * \mathrm{p}<0.01 ; * * * \mathrm{p}<0.001$. 
To examine this question, Table 5 provides both uncorrected and IPW-corrected estimates of the origins-destinations association among advanced degree holders. ${ }^{17}$ Although the uncorrected estimates in Table 5 are positive and the association is larger for men than for women, the estimates and the gender difference in the estimates are all statistically insignificant. This finding makes it difficult to compare my results directly with those reported by Torche (2011), as she uses a much larger sample. ${ }^{18}$ Nonetheless, correcting by IPW for the selection into this group, I do not find any evidence in favor of the origins-destinations association reemerging among advanced degree holders. In contrast, all IPW-corrected estimates are close to zero and statistically insignificant, a result that is replicated in an additional analysis that extends the analytical sample to include those aged 14 to 18 in 1979 (see the lower panel of Appendix Table A1). In sum, as a result of small sample sizes, I cannot draw any firm conclusions about whether the non-random selection into the sample of advanced degree holders affects the estimated origins-destinations association for this group.

\subsection{Income Mobility among College Graduates}

Social mobility is a broad concept whose definition largely depends on how the social positions, between which intergenerational movements occur, are measured (Torche 2015). To supplement my analyses of occupational mobility among college degree holders, I follow Torche (2011) and also examine intergenerational family income mobility. Table 6 presents the results. The intergenerational income elasticity in the full sample is 0.421 , suggesting that

\footnotetext{
17 About 11 percent is classified as advanced degree holders in the sample (i.e., as having at least 17 years of schooling). In Appendix Table A3, I report estimates from the logit model predicting the selection into this sample. ${ }^{18}$ Torche (2011) bases her study on the full NLSY79 sample, providing her with more statistical power. Even when I extend the sample to include those aged 14-18 in 1979, I still do not have sufficient statistical power to draw any firm conclusions.
} 
about 42 percent of the income inequality in the parents' generation is transmitted to the respondents' generation. While the elasticity is slightly larger for men than for women, the gender difference is not statistically significant at a 5-percent level.

In contrast to the analyses of occupational mobility presented above, among college degree holders, the uncorrected elasticities are about 20 percent and highly statistically significant. This result suggests that a college degree may not promote income mobility to the same extent as occupational mobility. Correcting by IPW for the selection into the college degree holder sample, I find virtually the same pattern, indicating that selectivity does not affect the estimated elasticities to any great extent. Two additional analyses corroborate this finding. First, analyses of college degree holders without an advanced degree (reported in Appendix Table A4) reveal a similar pattern. Second, analyses based on the extended analytical sample of all respondents aged 14 to 18 in 1979 (reported in Appendix Table A5) yield results very similar to those reported for those aged 14 to $16 .{ }^{19}$ In sum, the two additional analyses show that although parents' income appears to affect respondents' income among college degree holders, this transmission pattern is not greatly affected by the selectivity of the group.

\footnotetext{
${ }^{19}$ In appendix Tables A4 and A5, some of the elasticities tend to increase once I correct for the selection by IPW. Yet, as the IPW-corrected estimates have substantially larger standard errors, the confidence intervals overlap to such a large extent that I cannot draw any firm conclusions about the direction of change. I experimented with formally testing the difference between the uncorrected and IPW-corrected estimates, using a bootstrap estimator of the standard error of the difference between the two estimates within the multiple imputation setup. In all situations, the difference was statistically insignificant.
} 


\begin{tabular}{lllllll}
\hline & All & \multicolumn{2}{c}{ Men } & \multicolumn{3}{c}{ Women } \\
\cline { 2 - 7 } & $\mathrm{b}$ & $\mathrm{SE}$ & $\mathrm{b}$ & $\mathrm{SE}$ & $\mathrm{b}$ & $\mathrm{SE}$ \\
\hline Full sample & $0.421^{* * *}$ & 0.028 & $0.444 * * *$ & 0.041 & $0.399 * * *$ & 0.036 \\
College degree holders & & & & & & \\
Uncorrected & $0.213^{* * * *}$ & 0.046 & $0.208^{* *}$ & 0.072 & $0.217^{* * *}$ & 0.061 \\
IPW corrected & $0.223^{* * *}$ & 0.066 & $0.225^{*}$ & 0.094 & $0.215^{*}$ & 0.087 \\
\hline
\end{tabular}

Table 6. Intergenerational Family Income Elasticity among College Degree Holders (Regression Coefficients and Standard Errors)

Notes: Respondents aged 14-16 in 1979. Multiply imputed data using 25 datasets. Estimates corrected for complex survey design.

$* \mathrm{p}<0.05 ; * * \mathrm{p}<0.01 ; * * * \mathrm{p}<0.001$

\section{Discussion}

This paper examines whether the selectivity of college degree holders can account for the high levels of social mobility reported for this group in previous research. If selectivity can account for this pattern, then college may be nothing more than an effective sorting mechanism that has little meritocratic power in terms of fostering social mobility. In contrast to previous research, I provide a direct test of the hypothesis using inverse probability weights to control for the nonrandom selection into college on a range of observed characteristics such as skills and expectations measured before respondents go to college. My empirical analysis yields clear evidence against the selectivity hypothesis. Controlling for the non-random selection into the college graduate sample does not change the magnitude of the estimated origins-destinations association among college degree holders. This conclusion also holds once I break down college degree holders to those with and without an advanced degree, and when I consider the intergenerational transmission of family income instead of occupational status. Thus, my 
findings suggest that college is an equalizer, consistent with the results reported in the literature (Hout 1988; Torche 2011).

A key finding in Torche (2011) is that the intergenerational association follows a Ushape pattern in which the origins-destinations associations reemerge among advanced degree holders. My empirical analysis can neither confirm nor contradict this finding, primarily because I use a smaller sample (restricted to those aged 14-16 in 1979). On the one hand, the statistically insignificant IPW-corrected estimates of the origins-destinations association among advanced degree holders suggest that—net of selection into this very selected sample-an advanced degree appears to be as powerful an equalizer as a regular college degree. However, because I cannot identify the U-shape patterns in the models for which I do not control for the selection into the group, my analysis does not offer any definitive evidence that the reemergence of the origins-destinations association among advanced degree holders is a result of selective attrition.

A limitation of my study is that I can only control for selective attrition on observed covariates. Although the data I use include a range of observed characteristics that the previous literature has identified as being powerful predictors of college completion, I may have omitted covariates that also are powerful predictors of college completion, but which are not available in the data. While I cannot remedy this situation in the current study, future research should consider employing methods and data that allow one to correct for selection in completing college on unobserved variables. Heckman's two-step sample selection model would be a natural choice, although it requires a credible instrumental variable that affects college completion but not occupational destinations. Collecting such data would consequently be key if a more rigorous test of the selectivity hypothesis should be carried out. 
A further limitation of my study pertains to the way in which I measure occupational mobility (i.e., the association between occupational origins and destinations). While I use Duncan's SES for this purpose, Hout (1988) uses a discrete social class scheme [i.e., a 14category classification scheme based on the class scheme in Blau and Duncan (1967) and Featherman and Hauser (1978)], and Torche (2011) uses the Erikson-Goldthorpe-Portocarero class scheme in addition to using Duncan's SES. Therefore, the conclusions that I draw from my empirical analyses do not necessarily generalize to occupational class mobility. However, as the NLSY79 does not include information on whether or not parents are self-employed, I cannot reconstruct the class measures that Hout and Torche use, making it very difficult to investigate whether my results generalize to occupational class mobility. ${ }^{20}$ Nonetheless, as Torche's (2011) results indicate, education's impact on the intergenerational class association is very similar to its impact on the intergenerational SES association. As a consequence, one might not expect large differences in the results to arise if my approach was applied to class mobility. Still, as this question ultimately is an empirical one, future research should consider answering it by applying my approach to occupational class mobility using appropriate data.

This study's methodological approach may aid future comparative research on the role of education in social mobility. Hout (1988) argued that, because social mobility is much higher among highly educated individuals, as countries' populations become more educated over time, the net level of social mobility should also increase over time (Breen 2010; Breen and Jonsson 2007). However, this argument depends on the assumption that the mobility-promoting effects of college do not change over time as college becomes less selective. Although my study says little about changes over time, future research may apply my study's approach to examine this

\footnotetext{
${ }^{20}$ Torche (2011) analyzes class mobility using the General Social Surveys, not the NLSY79.
} 
question analyzing data from different cohorts, periods, or countries, although such analyses would put high demands on collecting comparable data.

The key question of this paper is how the non-random selection into college affects the origins-destinations association. However, as Goldthorpe (2007) points out, we may interpret the interaction term involving education and social origins in the opposite way by examining how the occupational returns to college (i.e., the effect of college on destinations) vary by social origins. ${ }^{21}$ In terms of Hout's (1988) finding of declining origins-destinations associations by educational level, the interaction term implies that low-SES individuals have a higher return to college than high-SES individuals. However, this conclusion depends critically on how the returns to education are estimated. One potential way would be to use inverse probability weighting to estimate the returns to college by different levels of social origins. Such an approach would control for regular selection bias that occurs in determining the returns to schooling (Cole and Hernan 2008).

From this perspective, my study also speaks to the larger issue of determining the role of education in social mobility. The conventional approach is to examine the extent to which education mediates the origins-destinations association using data on origins, destinations, and education. Such mediation analysis depends in part on estimating the "occupational destinations returns" to education. However, as work in labor economics shows, estimating the causal returns to education requires correcting for the endogenous or non-random nature of schooling (Card 1999). The mediating role of education in social mobility may therefore be overestimated in studies using conventional mediation analysis as they likely overestimate the

\footnotetext{
${ }^{21}$ While sociologists appear to have given this interpretation of the interaction relatively little attention, labor economists have examined this question using siblings and twins (Altonji and Dunn 1996; Ashenfelter and Rouse 1998).
} 
returns to education. Although the approach I apply in this paper cannot immediately be applied to this line of inquiry, future research should consider ways of extending the approach to control for the non-random selection into schooling when examining education's mediating role in social mobility. 


\section{References}

Altonji, Joseph G., and Thomas A. Dunn. 1996. "The Effects of Family Characteristics on the Return to Education." Review of Economics and Statistics 78(4):692-704.

Ashenfelter, Orley, and Cecilia Elena Rouse. 1998. "Income, Schooling, and Ability: Evidence from a New Sample of Identical Twins." Quarterly Journal of Economics 113(452):253-84.

Berk, Richard A. 1983. "Introduction to Sample Selection Bias in Sociological Data." American Sociological Review 48(3):386-98.

Bills, David B., Valentina Di Stasio, and Klarita Gërxhani. 2017. "The Demand Side of Hiring: Employers in the Labor Market.” Annual Review of Sociology 43:291-310.

Borghans, Lex, Angela Lee Duckworth, James J. Heckman, and Bas ter Weel. 2008. "The Economics and Psychology of Personality Traits.” Journal of Human Resources 43(4):9721059.

Blau, Peter M. and Otis D. Duncan. 1967. The American Occupational Structure. New York: Free Press.

Brand, Jennie E. 2010. "Civic Returns to Higher Education: A Note on Heterogeneous Effects." Social Forces 89(2):417-33.

Brand, Jennie, and Yu Xie. 2010. "Who Benefits Most from College? Evidence for Negative Selection in Heterogeneous Economic Returns to Higher Education." American Sociological Review 75(2):273-302.

Breen, Richard. 2010. "Educational Expansion and Social Mobility in the 20th Century." Social Forces 89(2):365-88.

Breen, Richard, Seongsoo Choi, and Anders Holm. 2015. "Heterogeneous Causal Effects and Sample Selection Bias." Sociological Science 2(17):351-69.

Breen, Richard, and Jan O. Jonsson. 2005. "Inequality of Opportunity in Comparative Perspective: Recent Research on Educational Attainment and Social Mobility." Annual Review of Sociology 31(1):223-43.

—. 2007. "Explaining Change in Social Fluidity: Educational Equalization and Educational Expansion in Twentieth-Century Sweden1." American Journal of Sociology 112(6):1775810.

Buis (Ed.), Maarten. 2011. Research in Social Stratification: Special Issue on Unobserved Heterogeneity in Mare Models.

Cameron, Stephen V., and James J. Heckman. 1998. "Life Cycle Schooling and Dynamic Selection Bias: Models and Evidence for Five Cohorts of American Males." The Journal of Political Economy 106(2):262-333.

Card, David. 1999. "The Causal Effect of Education on Earnings." Pp. 1801-63 in Handbook of Labor Economics, edited by Orley Ashenfelter and David Card. Amsterdam: NorthHolland.

Carneiro, Pedro, James J. Heckman, and Edward J. Vytlacil. 2011. "Estimating Marginal Returns to Education." aer American Economic Review 101(6):2754-81. 
Cole, S. R., and M. A. Hernan. 2008. "Constructing Inverse Probability Weights for Marginal Structural Models.” American journal of epidemiology 168(6):656-64.

DiMaggio, Paul. 1982. "Cultural Capital and School Success: The Impact of Status Culture Participation on the Grades of U.S. High School Students." American Sociological Review 47(2):189-201.

Erikson, Robert, and Jan O. Jonsson. 1998. "Qualifications and the Allocation Process of Young Men and Women in the Swedish Labour Market.” Pp. 369-406 in From School to Work. A Comparative Study of Educational Qualifications and Occupational Destinations, edited by Yossi Shavit and Walter Müller. Oxford: Oxford University Press.

Farkas, George. 2003. "Cognitive Skills and Noncognitive Traits and Behaviors in Stratification Processes.” Annual Review of Sociology 29:541-62.

Featherman, David L. and Robert M. Hauser. 1978. Opportunity and Change. New York: Academic Press.

Goldthorpe, John H. 2007. On Sociology. Stanford, CA: Stanford University Press.

Heckman, James J. 1979. "Sample Selection Bias as a Specification Error.” Econometrica 47(1):153-61.

Heckman, James J., Jora Stixrud, and Sergio Urzua. 2006. "The Effects of Cognitive and Noncognitive Abilities on Labor Market Outcomes and Social Behavior." Journal of Labor Economics 24(3):411-82.

Holm, Anders, and Mads M. Jæger. 2011. "Dealing with selection bias in educational transition models: The bivariate probit selection model." Research in Social Stratification and Mobility 29(3):311-22.

Hout, Michael. 1988. "More Universalism, Less Structural Mobility: The American Occupational Structure in the 1980s." American Journal of Sociology 93(6):1358-400.

-. 2012. "Social and Economic Returns to College Education in the United States." Annual Review of Sociology 38:379-400.

Hout, Michael, and Thomas A. DiPrete. 2006. "What we have learned: RC28's contributions to knowledge about social stratification." Research in Social Stratification and Mobility 24(1):1-20.

Ishida, Hiroshi, Walter Müller, and John M. Ridge. 1995. "Class Origin, Class Destination, and Education: A Cross-National Study of Ten Industrial Nations." American Journal of Sociology 101(1):145-93.

Jackson, Michelle. 2007. "How far merit selection? Social stratification and the labour market." The British journal of sociology 58(3):367-90.

—. 2009. "Disadvantaged through discrimination? The role of employers in social stratification." The British journal of sociology 60(4):669-92.

Jencks, Christopher. 1972. Inequality : a reassessment of the effect of family and schooling in America. New York: Basic Books.

Lawrence, Matthew, and Richard Breen. 2016. "And Their Children after Them? The Effect of College on Educational Reproduction.” American Journal of Sociology 122(2):532-72. 
Lucas, Samuel R., Phillip N. Fucella, and Mark Berends. 2011. "A neo-classical education transitions approach: A corrected tale for three cohorts." Research in Social Stratification and Mobility 29(3):263-85.

Mare, Robert D. 1980. "Social Background and School Continuation Decisions." Journal of the American Statistical Association 75(370):295-305.

—. 1981. "Change and Stability in Educational Stratification." American Sociological Review 46(1):72-87.

- 1993. "Educational stratification on observed and unobserved components of family background." Pp. 351-76 in Persistent inequality: Changing educational attainment in thirteen countries, edited by Yossi Shavit and Hans-Peter Blossfeld. Boulder, Colo.: Westview Press.

-. 2011. "Introduction to symposium on unmeasured heterogeneity in school transition models." Research in Social Stratification and Mobility 29(3):239-45.

Mare, Robert D., and Vida Maralani. 2006. "The intergenerational effects of changes in women's educational attainments." American Sociological Review 71:542-64.

Morgan, Stephen L. 2004. "Methodologist as Arbitrator: Five Models for Black-White Differences in the Causal Effect of Expectations on Attainment." Sociological Methods \& Research 33(1):3-53.

Pfeffer, Fabian T., and Florian R. Hertel. 2015. "How Has Educational Expansion Shaped Social Mobility Trends in the United States?" Social Forces 94(1):143-80.

Roksa, Josipa, Eric Grodsky, Richard Arum, and Adam Gamoran. 2007. "United States: Changes in Higher Education and Social Stratification." Pp. 165-91 in Stratification in higher education: A comparative study, edited by Yossi Shavit, Richard Arum, and Adam Gamoran. Stanford, CA: Stanford University Press.

Seaman, S. R., and I. R. White. 2013. "Review of inverse probability weighting for dealing with missing data." Statistical methods in medical research 22(3):278-95.

Sewell, William Hamilton, Archibald O. Haller, and Alejandro Portes. 1969. "The educational and early occupational attainment process." American Sociological Review 34(1):82-92.

Torche, Florencia. 2011. "Is a College Degree Still the Great Equalizer? Intergenerational Mobility across Levels of Schooling in the United States." American Journal of Sociology 117(3):763-807.

—. 2015. "Analyses of Intergenerational Mobility : An Interdisciplinary Review." The ANNALS of the American Academy of Political and Social Science 657(1):37-62.

Vallet, Louis-Andres. 2004. "Change in Intergenerational Class Mobility in France from the 1970s to the 1990s and Its Explanation: An Analysis Following the CASMIN Approach." Pp. 115-47 in Social mobility in Europe, edited by Richard Breen. Oxford: Oxford University Press.

von Hippel, Paul T. 2007. "Regression with Missing Ys: An Improved Strategy for Analyzing Multiply Imputed Data." Sociological Methodology Sociological Methodology 37(1):83-117. 
Wooldridge, Jeffrey M. 2010. Econometric analysis of cross section and panel data. Cambridge, Mass.: MIT Press.

Yamaguchi, Kazuo. 1983. "The Structure of Intergenerational Occupational Mobility: Generality and Specificity in Resources, Channels and Barriers." American Journal of Sociology 88(4):718-45.

Zimmerman, S. D. 2014. "The returns to college admission for academically marginal students." Journal of Labor Economics 32(4):711-54. 


\section{Appendix}

\begin{tabular}{|c|c|c|c|c|c|c|}
\hline & \multicolumn{2}{|l|}{ All } & \multicolumn{2}{|l|}{ Men } & \multicolumn{2}{|l|}{ Women } \\
\hline & $\mathrm{b}$ & SE & $\mathrm{b}$ & SE & $\mathrm{b}$ & SE \\
\hline Full sample & $0.309 * * *$ & 0.016 & $0.373 * * *$ & 0.024 & $0.239 * * *$ & 0.021 \\
\hline \multicolumn{7}{|c|}{ College degree holders } \\
\hline Uncorrected & 0.054 & 0.029 & 0.076 & 0.043 & 0.033 & 0.039 \\
\hline IPW-corrected & 0.044 & 0.059 & 0.095 & 0.085 & -0.0011 & 0.066 \\
\hline \multicolumn{7}{|c|}{ College degree holders without advanced degree } \\
\hline Uncorrected & 0.021 & 0.038 & 0.041 & 0.058 & 0.002 & 0.050 \\
\hline IPW-corrected & -0.009 & 0.093 & 0.049 & 0.132 & -0.046 & 0.098 \\
\hline \multicolumn{7}{|c|}{ Advanced Degree Holders } \\
\hline Uncorrected & 0.070 & 0.041 & 0.075 & 0.057 & 0.061 & 0.062 \\
\hline IPW-corrected & -0.052 & 0.067 & -0.085 & 0.099 & 0.010 & 0.075 \\
\hline
\end{tabular}

Table A1. Intergenerational SES Associations in Full Sample, among College Degree Holders and Advanced Degree Holders: Analytical Sample Extended to Include All Respondents Aged 14-18 in 1979 (Regression Coefficients and Standard Errors)

Notes: Respondents aged 14-18 in 1979. Multiply imputed data using 25 datasets. Estimates corrected for complex survey design.

$* \mathrm{p}<0.05 ; * * \mathrm{p}<0.01 ; * * \mathrm{p}<0.001$. 


\begin{tabular}{|c|c|c|}
\hline & $\mathrm{b}$ & SE \\
\hline Origin SES & 0.179 & 0.097 \\
\hline Origin family income (log) & 0.051 & 0.160 \\
\hline Cognitive ability & $0.959 * * *$ & 0.127 \\
\hline Cognitive ability squared & $-0.341 * * *$ & 0.081 \\
\hline Locus of control & -0.040 & 0.070 \\
\hline Self-esteem & -0.112 & 0.077 \\
\hline Cultural capital & 0.020 & 0.091 \\
\hline Educational expectations & $2.350 * * *$ & 0.689 \\
\hline Educational expectations squared & $-0.073^{* *}$ & 0.023 \\
\hline Friends' ed. expectations & $1.841 *$ & 0.725 \\
\hline Friends' ed. expectations squared & $-0.063^{*}$ & 0.025 \\
\hline Significant others' influence & 0.288 & 0.199 \\
\hline Male & 0.124 & 0.142 \\
\hline \multicolumn{3}{|l|}{ Race/ethnicity } \\
\hline White (ref.) & - & - \\
\hline Black & $0.817 * * *$ & 0.220 \\
\hline Hispanic & -0.123 & 0.302 \\
\hline Father's schooling & 0.011 & 0.030 \\
\hline Mother's schooling & -0.008 & 0.038 \\
\hline Number of siblings & -0.052 & 0.035 \\
\hline Intact family & 0.123 & 0.193 \\
\hline Foreign language in home & -0.120 & 0.254 \\
\hline \multicolumn{3}{|l|}{ Rural-urban indicator } \\
\hline Not in SMSA (ref.) & - & - \\
\hline SMSA — not a central city & -0.041 & 0.178 \\
\hline SMSA - central city unknown & -0.065 & 0.197 \\
\hline SMSA — in central city & -0.246 & 0.249 \\
\hline Intercept & -36.189 & 6.133 \\
\hline Pseudo R-squared ${ }^{a}$ & $19.6 \%$ & \\
\hline
\end{tabular}

Table A2. Logit Model Predicting Probability of Being in Sample of College Degree Holders without Advanced Degree (Logit Coefficients and Standard Errors)

Notes: Respondents aged 14-16 in 1979. Multiple imputation and 1979 sampling weights used. ${ }^{a}$ Average McFadden's pseudo R-squared over the 25 imputations.

${ }^{*} \mathrm{p}<0.05 ; * * \mathrm{p}<0.01 ; * * \mathrm{p}<0.001$. 


\begin{tabular}{|c|c|c|}
\hline & $\mathrm{b}$ & SE \\
\hline Origin SES & $0.332 * *$ & 0.116 \\
\hline Origin family income (log) & 0.018 & 0.199 \\
\hline Cognitive ability & $0.826 * * *$ & 0.120 \\
\hline Locus of control & -0.024 & 0.091 \\
\hline Locus of control squared & $-0.150 *$ & 0.070 \\
\hline Self-esteem & $0.186^{*}$ & 0.090 \\
\hline Cultural capital & $0.232 *$ & 0.118 \\
\hline Educational expectations & $0.246 * * *$ & 0.058 \\
\hline Friends' ed. expectations & 0.080 & 0.048 \\
\hline Significant other's influence & 0.362 & 0.247 \\
\hline Male & $-0.347^{*}$ & 0.172 \\
\hline \multicolumn{3}{|l|}{ Race/ethnicity } \\
\hline White (ref.) & - & - \\
\hline Black & $0.553^{*}$ & 0.282 \\
\hline Hispanic & 0.252 & 0.354 \\
\hline Father's schooling & 0.034 & 0.038 \\
\hline Mother's schooling & $0.155^{* * *}$ & 0.045 \\
\hline Number of siblings & -0.045 & 0.045 \\
\hline Intact family & 0.134 & 0.237 \\
\hline Foreign language in home & $0.769 * *$ & 0.263 \\
\hline \multicolumn{3}{|l|}{ Rural-urban indicator } \\
\hline Not in SMSA (ref.) & - & - \\
\hline SMSA - not a central city & -0.177 & 0.212 \\
\hline SMSA - central city unknown & $-0.694 *$ & 0.276 \\
\hline SMSA - in central city & -0.045 & 0.294 \\
\hline Intercept & $-10.027 * * *$ & 2.272 \\
\hline Pseudo R-squared ${ }^{\mathrm{a}}$ & $33.7 \%$ & \\
\hline
\end{tabular}

Table A3. Logit Model Predicting Probability of Holding Advanced Degree (Logit Coefficients and Standard Errors)

Notes: Respondents aged 14-16 in 1979. Multiple imputation and 1979 sampling weights used. aAverage McFadden's pseudo R-squared over 25 imputations.

$* \mathrm{p}<0.05 ; * * \mathrm{p}<0.01 ; * * * \mathrm{p}<0.001$. 


\begin{tabular}{lcccccc}
\hline & \multicolumn{1}{c}{ All } & \multicolumn{2}{c}{ Men } & \multicolumn{3}{c}{ Women } \\
\cline { 2 - 7 } & $\mathrm{b}$ & $\mathrm{SE}$ & $\mathrm{b}$ & $\mathrm{SE}$ & $\mathrm{b}$ & $\mathrm{SE}$ \\
\hline Full sample & $0.421^{* * *}$ & 0.028 & $0.444^{* * *}$ & 0.041 & $0.399^{* * *}$ & 0.036 \\
College degree holders without advanced degree & & & & \\
Uncorrected & $0.234^{* * *}$ & 0.061 & $0.187^{*}$ & 0.093 & $0.272^{* * *}$ & 0.080 \\
IPW-corrected & 0.245 & 0.128 & 0.221 & 0.207 & $0.256^{*}$ & 0.117 \\
Advanced degree holders & & & & & & \\
Uncorrected & & & & & & 0.092 \\
IPW-corrected & $0.177 *$ & 0.072 & $0.219 *$ & 0.108 & 0.135 & 0.125 \\
\hline
\end{tabular}

Table A4. Intergenerational Family Income Elasticity in Full Sample among College Degree Holders without Advanced Degree and with Advanced Degree Holders (Regression Coefficients and Standard Errors)

Notes: Respondents aged 14-16 in 1979. Multiply imputed data using 25 datasets. Estimates corrected for complex survey design.

$* \mathrm{p}<0.05 ; * \mathrm{p}<0.01 ; * * * \mathrm{p}<0.001$. 


\begin{tabular}{|c|c|c|c|c|c|c|}
\hline & \multicolumn{2}{|l|}{ All } & \multicolumn{2}{|l|}{ Men } & \multicolumn{2}{|l|}{ Women } \\
\hline & $\mathrm{b}$ & SE & $\mathrm{b}$ & $\mathrm{SE}$ & $\mathrm{b}$ & SE \\
\hline Full sample & $0.383 * * *$ & 0.021 & $0.400 * * *$ & 0.029 & $0.366 * * *$ & 0.028 \\
\hline \multicolumn{7}{|c|}{ College degree holders } \\
\hline Uncorrected & $0.207 * * *$ & 0.039 & $0.208 * *$ & 0.059 & $0.204 * * *$ & 0.050 \\
\hline IPW-corrected & $0.243 * * *$ & 0.067 & $0.293 * *$ & 0.105 & $0.201 *$ & 0.083 \\
\hline \multicolumn{7}{|c|}{ College degree holders without advanced degree } \\
\hline Uncorrected & $0.220 * * *$ & 0.051 & $0.195^{*}$ & 0.079 & $0.243 * * *$ & 0.068 \\
\hline IPW-corrected & $0.264 *$ & 0.110 & 0.287 & 0.179 & $0.249^{*}$ & 0.106 \\
\hline \multicolumn{7}{|c|}{ Advanced degree holders } \\
\hline Uncorrected & $0.181 * *$ & 0.059 & $0.219^{*}$ & 0.087 & 0.146 & 0.077 \\
\hline IPW-corrected & $0.206^{*}$ & 0.099 & $0.256^{*}$ & 0.113 & 0.153 & 0.151 \\
\hline
\end{tabular}

Table A5. Intergenerational Family Income Elasticity among Full Sample, College Degree Holders, and Advanced Degree Holders: Analytical Sample Extended to Include All Respondents Aged 14-18 in 1979 (Regression Coefficients and Standard Errors) Notes: Respondents aged 14-18 in 1979. Multiply imputed data using 25 data sets. Estimates corrected for complex survey design.

$* \mathrm{p}<0.05 ; * * \mathrm{p}<0.01 ; * * * \mathrm{p}<0.001$. 